\title{
A Study on the Quality systems-Modal for Quality Management of Manufacturing
}

\author{
Qi Liang \& Yukan Hou \\ Northwestern Polytechnical University, Xi'an 710072, China \\ E-mail: lqnwpu@nwpu.edu.cn
}

\begin{abstract}
This paper outlines a study of the quality systems-model for quality management and quality assurance of manufacturing. The study presents as processes being closed-loop in nature. Comprehensive studies were made in connection with the general and practical ways of the quality management to deal with design of advanced making system. The thrifty quality management system may be simplified shall be structured and adapted to the activities and size of the particular organization.
\end{abstract}

Keywords: Quality management; Improvement model; organization; Process management

With the rapid development of advanced making, the study on the quality systems-model has become a new topic of project management domain.

The various quality systems-models are must introduced for various field and style and size project.

Problems associated with the quality failure have been caused by the quality systems-model itself and by the failings of the people charged with development.

Academic investigation is constrained by similar intellectual inadequacies. The following paragraphs therefore represent a modest but synoptic attempt not to resolve completely, but to clearly enunciate this problem. Using the 'quality' concept as a fulcrum for discussion, we trace lines of argument from its existence as a management fact, backward to its origins within systems-model and forward to its effects on quality.

In recent years many making factories of our county have been faced with the problem of how to introduce new quality systems-model and to make product higher.

The reasons for the failure that quality systems have sustained stable quality conformity are varied. The first and most obvious result is that improvement in quality assurance will never be unable to keep up with the free market's appetite. Second, as procedures process model need depend upon the complexity closes the loop of the work, improvement of process model will usually need a period even a few period. And finally, a large system will result in raising greatly costs. Some people claim that the solution is to pass ISO certification. But certification does not full lead to higher quality.

Because the needs of organizations vary, it is not the purpose of this International Standard to imply uniformity of quality management systems. The model of an organization's quality management system should be configured in a manner that is appropriate to its unique activities.

In recent years, China has experienced development boom in quality certification of ISO that has impetus to many technological fields and especially to the quality management. The ISO 9000 family of standards has been developed to help organization improve quality, communication and competitiveness in national, regional and international trade.

Sine the document is generic in nature and intent, only generic guidance is presented. An organization doesn't be stressed to implement unnecessary requirement under this International Standard. For each organization, it is intended that all requirements of this International Standard be applied. However, tailoring may be acceptable in certain situations. Each organization will need to select and employ the most appropriate methods and tools from the content of this International Standard. The organization shall establish a quality management as a means of ensuring that the product and/or service conform to requirements. The quality management system shall be structured and adapted to the activities and size of the particular organization. 
We need search for the pipes that can transfer our information of quality, and the ways we will apply them to give us the speed, reliability and security we need in quality management system. The quality systems-model for quality management provides a challenge to the people who develop it. We have accepted the task of the quality systems-model for quality management.

What is the idea about 'quality'? There are many different interpretations such as degree of excellence, fitness for purpose, value for money and conformance to specification or requirement. This can create confusion and misunderstanding.

Within the ISO 9000 family of standards, the term 'quality' is used in the context of achieving sustained customer satisfaction through meeting customer needs and expectations within an organizational environment committed to continual improvement of efficiency and effectiveness. Quality, in this sense, is critical to business success. Customer needs and expectations are typically expressed in the form of specified requirements. Such requirements typically contain relevant characteristics and their values.

A customer can be regarded as internal or external to the organization. Customer is used in a 'process' sense in which an organization is made up of a cascade of processes. Each and every process within an organization has both a supplier and a customer. Each and every customer has apperception of 'process' that the supplier should aim to meet in the most efficient and effective manner.

We know that a process is using resources to transform input into output. An output from one process can be an input to another process. In this way, many processes can be combined in a process chain. (See Figure)

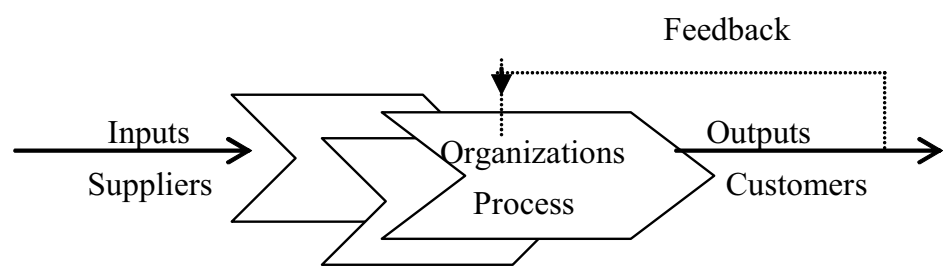

Figure 1. Process and Feedback Model Chain

To ensure all processes be operated as an efficient network the organization ought to undertake an analysis of how all processes, inputs and outputs interrelate. As an example, figure 1 shows the organization in a 'process and feedback model chain' relationship between a supplier and a customer. Note that the feedback inputs and outputs flow in different directions in the Figure.

Leading and operating an organization successfully requires managing in a systematic and visible model. Success can result from implementing and maintaining a management system that is designed to continually improve performance by addressing the needs of all customers. Quality management process model displayed in Figure is a new conceptual presentation of the quality management system requirements specified in International Standard. The model reflects graphically, the integration of essential content in quality management system.

Simultaneity, the organization should consider establishing channels for communication with all interested parties to enable timely transfer of information and informed responses well by all parties.

This process model is to be generally meaningful. By far the greatest usage of process model occur we designing system in order to decide the path of quality management systems and improvement. All elements of a complete quality management system may be placed within this quality management process model. It is an effective to reduce quality management processes or systems, time, cost and risk.

Quality management system is a logical rather than a physical system element; therefore, success is measured by the quality of a single entity rather than many manufactured entities. The quality management system does not wear out. If faults are encountered, there is high probability that each was inadvertently introduced during development and went undetected during testing.

You replace defective parts during the quality management system maintenance, but you have few, if any, spare parts. That is maintenance often includes correction or modification to design. The organization should initiate technical and administrative disciplines to control changes during design and development processes. Such changes should be determined, recorded, reviewed and approved by appropriate personnel before their implementation. Personnel should have the organizational freedom to raise and resolve quality problems.

To minimize effects of errors and to maximize productivity, verification should be carried out at important points in the processing sequence. Verification at each stage should relate directly to finished product and/or service specifications or an internal requirement, as appropriate. 
Upper-level managers with no background in quality systems-model for quality management are often given responsibility for system development. If he or she is willing to learn the ways that can be used to quality systems-model for quality management, apply effective methods of control, disregard mythology, and become conversant in a rapidly changing technology.

A manager of quality management should be appointed for the purpose of coordinating quality activities, awareness of interested parties' expectations and reporting to the top management. The manager should be informed of all quality problems, monitoring and reporting on the level of achievements against the quality objective, determining opportunities for quality improvement, monitoring and reporting on quality-related customer relations, managing the internal audit system, aggregating customer needs and expectations that are not part of their explicit requirement, participating in all management meetings where quality matters are discussed. Top management shall demonstrate that customer needs and expectations have been determined and translated into applicable customer requirements. The manager must communicate with all constituencies involved with system development-customer, system developers, support staff, and others. Communication can break down because the special characteristics of the quality systems-model for quality management and the particular problems associated with its development are misunderstood. When this occurs, the problems associated with the quality systems-model for quality management crisis are exacerbated

To leverage this power of quality management, we'll need to make our quality systems-model considerably easier to use than they are today. Quality should be built in to all organizational processes. Inadequate planning and operation of any process could lead to deterioration of capability and potential loss of efficiency.

Therefore, the top management, at defined intervals sufficient to ensure its continuing suitability, adequacy and effectiveness, should review the quality management system.

The development of quality systems-model for quality management compels us to accept responsibilities or give up. The final outcome, people would run a speed, reliability and security quality world.

\section{References}

ISO/TC207/SC1, ISO14001: 2004

ISO/TC176/SC1, ISO9000: 2000; ISO/TC176/SC2, ISO9001: 2000

Thiry M. (2003). For DAD: A programme management life-cycle process. International Journal of Project Management. 2003, 22(3). 